steroidal oestrogens may be more thrombogenic than natural conjugated oestrogens (M. Notelowitz, personal communication, 1972) the safety of non-steroidal over steroidal oestrogens has yet to be proved. Moreover, the relation between any oestrogen and thromboembolic disease has yet to be fully elucidated (Drill and Calhoun, 1972).

This preliminary study shows that P1496 is a satisfactory oestrogenic preparation without any notable side effects. With increasing knowledge of the endocrinological changes at the menopause and their relation to pathological changes there is need for a strict evaluation of all available oestrogenic substances, including P1496.

I thank Professor D. A. Davey, of the Department of Obstetrics and Gynaecology, University of Cape Town, for access to clinical material; Professor J. E. Kench and Dr. E. Simson, of the Department of Chemical Pathology, for routine laboratory estimations; Dr. L. Kaminsky and the Department of Physiology, for serum protein bound iodine estimations; the superintendent of Groote Schuur Hospital, for permission to report; and Sandoz Ltd., Basle, for provision of P1496 and help in data analysis.

\section{References}

Dowling, J. T., Freinkel, N., and Ingbar, S. H. (1956). Fournal of Clinical Endocrinology and Metabolism, 16, 280 .

Dowling, J. T., Freinkel, N., and Ingbar, S. H. (1960). fournal of Clinical Investigation, 39, 119.

Drill, V. A., and Calhoun, D. W. (1972). fournal of the American Medical Association, 219, 593 .

Duncan, E. J. (1959). South African Fournal of Medical Laboratory Technology, 5, 73 .

Fiske, C. H., and Subarrow, Y. (1929). fournal of Biological Chemistry, 81,

Frost, H. M. (1961). Fournal of the American Geriatric Society, 9, 1078

Gow, S., and MacGillivray, I. (1971). British Medical fournal, 2,73.

Kupperman, H. S., Blatt, M. H. G., Wiesbader, H., and Filler, W. (1953). fournal of Clinical Endocrinology and Metabolism, 13, 688 .

Lafferty, F. W., Spencer, G. E., and Pearson, D. H. (1964). American fournal of Medicine, 35, 514 .

Nordin, B. E. C. (1971). British Medical fournal, 1, 571.

Pearson, S., Stearn, J., and McGavak, T. A. (1953). Analytical Chemistry, 25, 813 .

Riley, M., and Gochman, N. (1964). In Technicon Symposium. Chertsey, Surrey, Technicon Instruments Co., Ltd.

Utian, W. H. (1971). South African Medical fournal, 45, 879.

Utian, W. H. (1972a) South African Medical fournal, 46,732.

Utian, W. H. (1972b). International fournal of Gynaecology and Obstetrics,

Utian, W. H. (1972c). South African fournal of Obstetrics and Gynaecology, 10,8 .

\title{
Modification of Plasma Corticosteroid Concentrations during and after Surgery by Epidural Blockade
}

\author{
N. H. GORDON, D. B. SCOTT, I. W. PERCY ROBB
}

British Medical fournal, 1973, 1, 581-583

\section{Summary}

The adrenocortical response to major surgery was assessed by the measurement of plasma corticosteroid concentrations in patients receiving either a general anaesthetic alone or in combination with an epidural block. The expected increase in plasma corticosteroid concentration seen in the general anaesthesia group was significantly inhibited by epidural block. The inhibition was related to the duration of the epidural block. The lack of the normal adrenocortical response to surgery was not associated with cardiovascular collapse and indeed did not seem detrimental in any way. These findings question the need for corticosteroid "cover" for the stress of surgery in patients who have been taking corticosteroid drugs.

\section{Introduction}

In response to major surgical procedures there is a rapid and sustained increase in the concentrations of plasma corticosteroid (Carter and James, 1970), corticotrophin (ACTH), and growth hormone (Ichikawa et al., 1971). A variety of stressful situations are known to increase the plasma corticosteroid concentration, among them preoperative apprehension. The main stimulus is, however, undoubtedly the surgical procedure itself.

University of Edinburgh, Edinburgh EH8 9YL

N. H. GORDON, M.B., F.F.A. R.C.S., Lecturer in Anaesthesia

I. W. PERCY ROBB, M.B., M.R.C.PATH., Senior Lecturer in Clinical Chemistry

Royal Infirmary of Edinburgh, Edinburgh EH3 9YW

D. B. SCOTT, M.D., F.F.A. R.C.S., Consultant Anaesthetist
Painful stimuli cause a rapid rise in plasma corticosteroid concentration which may be partly blocked by hypnotically suggested anaesthesia (Black and Friedman, 1968). The response is, however, not affected by deep ether anaesthesia (Oyama et al., 1968) or by spinal block used alone (Johnston, 1964).

We have studied the effects of epidural blockade in combination with general anaesthesia on the adrenocortical response to major surgery.

\section{Method}

Eighteen women undergoing abdominal hysterectomy were studied, whose only abnormalities were gynaecological. They were divided into three consecutive groups of six-group A receiving general anaesthetic alone, group $B$ receiving general anaesthetic plus a single dose epidural block, and group $C$ receiving general anaesthetic and a prolonged epidural block. All surgery was performed before 11 a.m. In group $A$, receiving general anaesthetic only, tubocurarine $30 \mathrm{mg}$ was given before tracheal intubation and the respiration controlled. The two other groups were allowed to breathe spontaneously without intubation. Lumbar epidural block was performed in the lateral position (20 $\mathrm{ml} \mathrm{2 \%} \mathrm{lignocaine).} \mathrm{Group} \mathrm{C}$ had an epidural catheter inserted, and 90 minutes after the initial injection they were given $10 \mathrm{ml}$ of $0.5 \%$ bupivacaine (without adrenaline). This produced sensory loss for up to four hours-that is, well into the postoperative period.

Venous blood (control sample) was withdrawn just before premedication (intramuscular diamorphine $5 \mathrm{mg}$ and atropine $0.6 \mathrm{mg}$ ) which was given one hour before surgery. A further blood specimen was taken just before induction of general anaesthesia (thiopentone $500 \mathrm{mg}$ followed by nitrous oxide, oxygen, and $1 \%$ halothane).

Further blood specimens were obtained immediately before the surgical incision and at 15-minute intervals during the operation. The length of operation was from 60 to 100 minutes 
Mean Plasma Corticosteroid Concentrations $(\mu \mathrm{g} / 100 \mathrm{ml}$ ) with Standard Deviations. Before Premedication (Control), Before Induction of General Anaesthesia, and Before and After the Surgical Incision in Three Groups Anaesthetized as shown

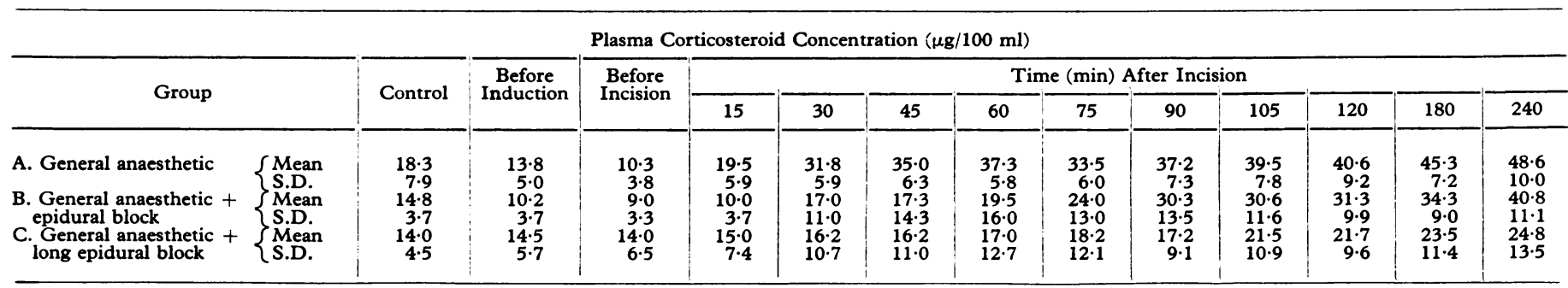

(average 76 minutes in group A, 60 minutes in group B, and 78 minutes in group $(C)$. During the postoperative period specimens were taken every 15 minutes during the first hour and then at hourly intervals for two hours.

Plasma corticosteroid concentrations were determined by the method of Mattingly (1962). Statistical analysis was performed using Student's $t$ test to compare groups and the paired Student's $t$ test in comparing data within a group.

\section{Results}

Mean corticosteroid concentrations, together with standard deviations, are shown in the table for the three groups of patients.

Changes in the mean corticosteroid concentrations from the control mean values are shown in fig. 1 . There was no significant difference in the plasma corticosteroid concentrations found in the three groups before premedication. Immediately before induction of anaesthesia the concentrations had fallen, and there was a further fall in the preoperative samples. The reduction of the corticosteroid concentrations before surgery was significantly lower than the control concentrations $(P<0.001)$.

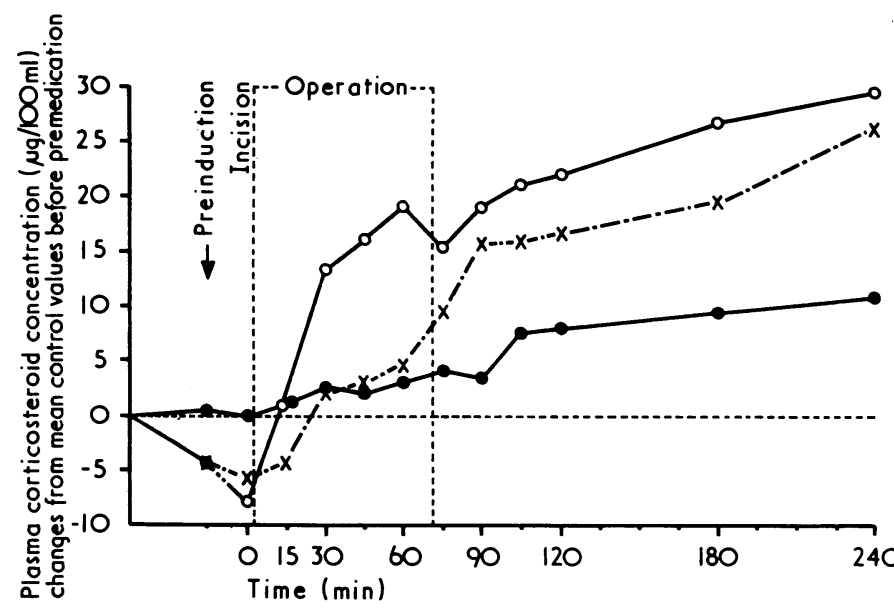

FIG. 1-Changes in mean corticosteroid concentrations before premedication, before incision, during operation, and during recovery from surgery in three groups of patients. $O=$ Group $A$, general anaesthetic alone. $X=$ Group B, general anaesthetic + epidural block. $=$ Group C, general anaesthetic + long epidural block.

\section{OPERATIVE SAMPLES}

In group $A$ the plasma corticosteroid concentrations rose sharply within 15 minutes and continued to rise during surgery, reaching a mean concentration of $37.3 \mu \mathrm{g} / 100 \mathrm{ml}$ after one hour. In both groups $B$ and $C$ there was a much smaller increase, the mean concentration reaching $19.5 \mu \mathrm{g} / 100 \mathrm{ml}$ in group $B$ and $17.0 \mu \mathrm{g} / 100 \mathrm{ml}$ in group $C$. These concentrations were sig- nificantly different from group $A$ in all the operative samples $(P<0.05)$ except the 15 -minute sample in group $C$.

\section{POSTOPERATIVE SAMPLES}

Plasma corticosteroid concentrations rose slowly in group A during the first three hours of the postoperative period, reaching a final mean concentration of $48.6 \mu \mathrm{g} / 100 \mathrm{ml}$. In group B the concentrations rose sharply and remained lower than in group A; the differences were no longer significant after the 90-minute samples. In group $C$ there was a gradual rise in plasma corticosteroid concentration but postoperative samples remained significantly lower than the corresponding levels in group A ( $P<0.05$ to $<0.001)$. The mean concentration in group $C$ three hours after operation was $24.8 \mu \mathrm{g} / 100 \mathrm{ml}$.

Examples of two types of response in group $\mathrm{C}$ are shown in fig. 2. Case 1 showed evidence of incomplete epidural blockade in that there was inadequate muscular relaxation for abdominal surgery, requiring a small dose $(30 \mathrm{mg})$ of the muscle relaxant gallamine.

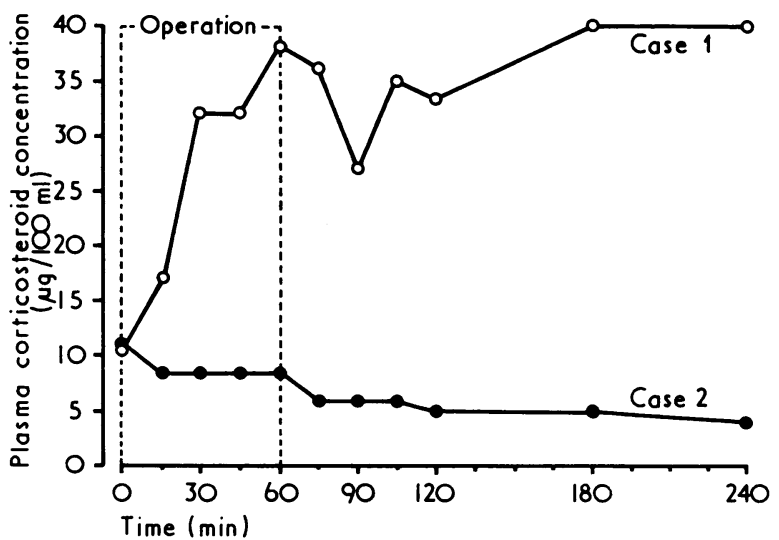

FIG. 2-Examples of plasma corticosteroid concentrations $(100 \mu / \mathrm{g} \mathrm{ml})$ in response to surgery in two patients who received general anaesthesia and prolonged epidural block. Case 1 showed evidence of incomplete epidural blockade.

No patient showed any clinical cause for concern during or after surgery, and the operative and postoperative progress was uneventful.

\section{Discussion}

The studies described here have been performed in patients receiving general anaesthetic supplemented in two groups by epidural block. Overall, corticosteroid concentrations fell in response to both premedication and general anaesthetic. Sleep disturbance and emotional stimuli promote a rise in plasma corticosteroids (Utting and Whiteford, 1972), and the fall found in most of our patients is presumably related to the suppression of anxiety by premedication. 
After surgical incision the expected (Carter and James, 1970) rise of plasma corticosteroid concentration occurred in those patients receiving general anaesthetic alone, but epidural block modified this response. Where the epidural block lasted only for the operative period the plasma corticosteroid concentration rose rapidly after surgery. Prolonged epidural block suppressed the rise so long as the block remained effective.

Previous studies on the effect of spinal anaesthesia on the adrenocortical response to surgery (Sandberg et al., 1954); Johnston, 1964) have shown inconsistent results. During spinal block these patients remained conscious and the hypothalamicpituitary-adrenal axis may be stimulated by mechanisms which include emotional stimuli and which would not be affected by spinal anaesthesia.

High transection of the spinal cord prevents the normal adrenocortical response to surgery (Hume et al., 1962). It is tempting to suggest that the adrenocortical response to trauma is mediated by nervous reflex linking the operation site with the central nervous system. In unconscious patients our finding was that the adrenocortical response was suppressed when the nervous pathways from the operation site were interrupted by epidural block.

Epidural and spinal block do not always produce total anaesthesia, and this may account for individual variations of corticosteroid response (fig. 2). Despite evidence of incomplete epidural blockade in case 1 and a similar case in group B, these two cases were not excluded from the series, although their omission might have increased the significant difference between group $A$ and groups $B$ and $C$. The other patient (case 2, fig. 2) may represent the effect of what was clinically complete epidural blockade. The absence of a rise in plasma corticosteroid concentration had no apparent effect on the reaction to major surgery in this patient, and her recovery was uneventful.

"Collapse" complicating surgery in patients receiving corticosteroid therapy has been recorded repeatedly over the last 20 years (Fraser et al., 1952). For this reason steroid cover for surgery has become routine (Bayliss, 1958) for all patients who have received corticosteroid therapy in the preceding two years. Close examination of the reports of collapse attributed to adrenocortical failure shows the relation to be based on circumstantial evidence (Cope, 1966). The first case report of collapse during surgery associated with a low adrenocortical steroid concentration (Sampson et al., 1961) responded to the intravenous administration of hydrocortisone. However, this therapy achieved steroid concentrations twice those normally found in response to surgery. The clinical improvement may have been similar to that seen in shocked patients treated with hydrocortisone who have normal adrenocortical function (Marks et al., 1959). Study of both medical and surgical patients with arterial hypotension due to suspected adrenocortical failure (Mattingly and Tyler, 1965) showed raised plasma corticosteroid concentrations in all 47 cases.

More recently modification to the prophylactic regimens has been suggested and, indeed, the necessity for cover in patients who have stopped corticosteroid therapy before surgery has been questioned (Plumpton et al., 1969). An adequate adrenocortical response to surgery was found in these patients.

In our patients in whom the expected adrenocortical response was inhibited by epidural block it was found that a low plasma corticosteroid concentration was not detrimental per se, was not associated with cardiovascular collapse during or after surgery, and it had no apparent effect on recovery from either anaesthesia or surgery.

The administration of supplementary corticosteroid drugs for the stress of surgery remains an open question.

We wish to thank Professor R. J. Kellar for allowing us to investigate his patients, and the department of medical illustrations, Edinburgh University, for their help.

\section{References}

Bayliss, R. I. S. (1958). British Medical Fournal, 2, 935.

Black, S., and Friedman, M. (1968). British Medical fournal, 1, 477.

Black, S., and Friedman, M. (1968). British Medical four

Carter, M. E., and James, V. H. (1970). Lancet, 1, 328

Fraser, C. G., Preuss, F. S., and Bigford, W. D. (1952). Fournal of the American Medical Association, 149, 1542.

Hume, D. M., Bull, C. C., and Bartter, F. (1962). Surgery, 52, 174.

Ichikawa, Y. Kawagoe, M., Nishikai, M., Yoshida, K. and Homma, M. (1971). Fournal of Laboratory and Clinical Medicine, 78, 882.

Johnston, I. D. A. (1964). Annals of the Royal College of Surgeons of England, 35, 270.

Marks, L. J., Donovan, M. J., Duncan, F., and Karger, R. (1959). Fournal of Clinical Endocrinology and Metabolism, 19, 1458.

Mattingly, D. (1962). Fournal of Clinical Pathology, 15, 374.

Mattingly, D., and Tyler, C. (1965). Proceedings of the Royal Society of Medicine, 58,1010 .

Oyama, T. et al. (1968). Anesthesiology, 29, 559

Plumpton, F. S., Besser, G. M., and Cole, P. V. (1969). Anaesthesia, 24, 3. Sampson, P. A., Brooke, B. N., and Winstone, N. E. (1961). Lancet, 1, 1377. Sandberg, A. A., Eiknes, K., Samuels, L. T., and Tyler, F. H. (1954) Fournal of Clinical Investigation, 33, 1509.

Fournal of Clinical Investigation, 33, 1509. British fournal of Anaesthesia,
Utting, J. E., and Whitford, J. H. W. (1972). Brite 44, 43.

\title{
Facial Sweating after Food: A New Sign of Diabetic Autonomic Neuropathy
}

\author{
P. J. WATKINS
}

British Medical fournal, 1973, 1, 583-587

\section{Summary}

Facial sweating during eating (gustatory sweating) has been observed for the first time in a group of diabetics, and is considered to be a feature of the autonomic neuropathy which affected them all. The sweating, which was sometimes very severe, was produced by

King's College Hospital, London SE5 9RS

P. J. WATKINS, M.D., M.R.C.P., Consultant Physician many foodstuffs, cheese being the most powerful stimulus. Atropine inhibited sweating stimulated by eating cheese, and oral anticholinergic drugs effectively eliminated the symptoms. These bizarre symptoms are probably due to abnormal nerve regeneration occurring as a consequence of the spontaneous autonomic neuropathy.

\section{Introduction}

Facial sweating during eating (gustatory sweating) is a normal response to highly spiced foods (Lee, 1954) and also occurs as an idiosyncrasy in some individuals, especially after chocolate 